\section{FRI0017 INFLIXIMAB (ANTI-TNF ALPHA ANTIBODY) TREATMENT FOR RHEUMATOID ARTHRITIS: INTERIM ANALYSIS OF A SPANISH COHORT STUDY PERFORMED IN ROUTINE PRACTICE. A MULTICENTER OPEN-LABEL STUDY OF THE CATALONIAN SOCIETY OF RHEMATOLOGY, CATALUNYA, SPAIN}

J Carbonell. Rheumatology, Hospital Del Mar, Barcelona; Hospital Mutua Terrassa; Hospital Vall d'Hebrón, Barcelona; Hospital Clínic, Barcelona; Hospital Parc Tauli, Sabadell; Clínica Girona; Hospital de Vic, Barcelona; Hospital de Malalties Reumàtiques, Barcelona; Hospital Sant Rafael, Barcelona, Spain

\subsection{6/annrheumdis-2001.1146}

\section{Background}

Objectives To evaluate the efficacy and safety of infliximab for RA in daily clinical practice.

Methods We included 54 patients with refractory RA who failed at least two different DMARDs (including MTX). The patients received $3 \mathrm{mg} / \mathrm{kg}$ infliximab at weeks $0,2,6$ and the every 8 weeks for 54 weeks. MTX and all other concomitant medications were kept at a stable during the study. Evaluations before each infusion included tender (TJC) and swollen joint counts (SJC), patient and physician global assessments, pain score (VAS), HAQ, morning stiffness, and ESR. All adverse events were recorded. We used the Wilcoxon test for two related samples to assess differences between measures taken in pairs.

Results All patients received at least 2 infusions and 9 patients completed the study through week 22 , when this analysis was done. ACR components including TJC, SJC, morning stiffness, patient and physician global assessments, VAS pain, ESR and the HAQ significantly decreased at week 2 (with $\mathrm{p}<0,001$ for all these ACR components), as it is shown in Table 1. At week 6, all these ACR components showed values significantly decreased ( $p$ $<0,001)$ with relation to week 0 but not in comparison with week 2 (except for TJC, SJC and physician global assessment with $\mathrm{p}<0,01)$. The results for clinical response and HAQ did not reach statistical significance after week 6 , due to the small number of patients that completed treatment in week 14 ( $\mathrm{n}=$ $24)$ and in week $22(n=9)$. One patient dropped out because of major surgery (related to the RA). The treatment was well tolerated; only minor adverse events $(n=15)$ without any serious infection were noted.

\begin{tabular}{llllll}
\multicolumn{6}{l}{ Abstract FRI0017 Table 1 } \\
\hline & Week $\mathbf{0}$ & Week 2 & Week 6 & Week 14 & Week 22 \\
& $\mathbf{n}=\mathbf{5 4}$ & $\mathbf{n = 5 4}$ & $\mathbf{n = 4 4}$ & $\mathbf{n = 2 4}$ & $\mathbf{n = 9}$ \\
\hline TJC & 17,0 & 14,0 & 8,0 & 4,5 & 8,0 \\
SJC & 12,0 & 7,0 & 5,0 & 5,0 & 7,0 \\
Morning stiffness & 60,0 & 15,0 & 7,5 & 10,0 & 15,0 \\
ESR & 48,0 & 30,0 & 35,0 & 32,0 & 33,0 \\
Patient Global Assesment & 68,5 & 48,0 & 49,5 & 32,0 & 36,0 \\
Physician Global Assesment & 66,5 & 50,0 & 46,5 & 46,0 & 49,0 \\
HAQ & 2,00 & 1,62 & 1,62 & 1,44 & 1,75 \\
\hline Median Values. & & & & &
\end{tabular}

Conclusion Patients with refractory rheumatoid arthritis significantly improve during therapy with infliximab. The observed beneficial effect is maintained during the treatment period without major adverse events.

\section{FRI0018 PROTECTION BY PHOSPHODIESTERASE-4 INHIBITOR ROFLUMILAST OF MICE AGAINST COLLAGEN-INDUCED ARTHRITIS}

1J Barsig, ${ }^{2} \mathrm{~B}$ Leung, ${ }^{1} \mathrm{DS}$ Bundschuh, ${ }^{1} \mathrm{~L}$ Wollin, ${ }^{1} \mathrm{R}$ Beume, ${ }^{2} \mathrm{FY}$ Liew. ${ }^{1}$ Department of Pharmacology, Byk Gulden, Konstanz, Germany; ${ }^{2}$ Department of Immunology, University of Glasgow, Glasgow, UK

\subsection{6/annrheumdis-2001.1147}

Background Orally available small molecular weight compounds with ability to suppress the proinflammatory mediator Tumour Necrosis Factor alpha (TNF) are of high interest for the treatment of rheumatoid arthritis (RA). Roflumilast (3-cyclopropylmethoxy-4-difluoromethoxy-N-[3,5-di-chloropyrid-4-yl]-benzamide) is a highly potent and selective inhibitor of phosphodiesterase type 4 (PDE4), that effectively suppresses TNF production in vitro and in vivo. ${ }^{1,2}$ This compound is currently in clinical development for asthma and COPD.

Objectives We investigated the capacity of Roflumilast to reduce the release of TNF in vivo in mice, and also examined its antiarthritic potential in murine collagen-induced arthritis (CIA).

Methods For induction of systemic TNF release, male BALB/c mice were injected intraperitoneally with lipopolysaccharide (LPS, S. abortus equi, $5 \mathrm{mg} / \mathrm{kg}$ ). Mice were orally treated with 1 or $10 \mathrm{mg} / \mathrm{kg}$ of Roflumilast $30 \mathrm{~min}$ prior to LPS challenge. Plasma was obtained $90 \mathrm{~min}$ after challenge for determination of cytokines by ELISA. CIA was induced in male DBA/ 1 mice by intradermal injection of $200 \mu \mathrm{g}$ of type II collagen (CII) in Freund?s complete adjuvant, followed by a booster injection of CII on day 21 (200 $\mu$ g in PBS i.p.). Roflumilast (1 or $5 \mathrm{mg} / \mathrm{kg}$ ) was given once daily p.o. on days $23 \square 33$. Arthritic scores (0\3) and paw thicknesses were monitored between days 21 139 . In parallel experiments, groups of mice were sacrificed and cells from draining lymph nodes were restimulated in vitro with graded concentrations of CII. TNF, Interleukin-6 (IL-6), and Interferon-gamma (IFN), released within $72 \mathrm{~h}$ of in vitro culture, were measured by ELISA. Histological analysis was performed on joints taken on day 35 after primary immunisation.

Results Roflumilast dose-dependently suppressed LPS-induced TNF production in vivo $(75 \%$ with $10 \mathrm{mg} / \mathrm{kg})$. By contrast, plasma levels of the anti-inflammatory cytokine Interleukin-10 were substantially raised $(500 \%$ with $10 \mathrm{mg} / \mathrm{kg})$. In addition, Roflumilast dose-dependently protected mice against CIA. This was also evident histologically by a significant reduction of joint inflammation and bone/cartilage erosion. The in vitro capacity of lymph node cells to produce TNF, IL-6, and IFN upon CII-stimulation was markedly reduced, even when cells were prepared one week after withdrawal of drug treatment.

Conclusion These data demonstrate that Roflumilast is a promising candidate for the oral treatment of rheumatoid arthritis.

\section{REFERENCES}

1 Bundschuh DS, et al. I Pharmacol Exp Ther., in press

2 Hatzelmann A, et al. J Pharmacol Exp Ther., in press

\section{FRI0019 EFFICACY OF ETANERCEPT ON TENOSYNOVITIS AND RHEUMATOID NODULES}

MJ Kaiser, MC Bozonnat, C Jorgensen, JP Daures, J Sany. Immuno-Rheumatology, Lapeyronie Hospital, Montpellier, France 